\title{
White-Light Emission and Tunable Luminescence Colors of Polyimide Copolymers Based on FRET and Room-temperature Phosphorescence
}

\author{
Mayuko Nara, Ryoji Orita, Ryohei Ishige, and Shinji Ando* \\ Department of Chemical Science and Engineering, School of Materials and Chemical \\ Technology, Tokyo Institute of Technology,
}

Ookayama 2-12-1-E4-5, Meguro-ku, Tokyo 152-8552, Japan
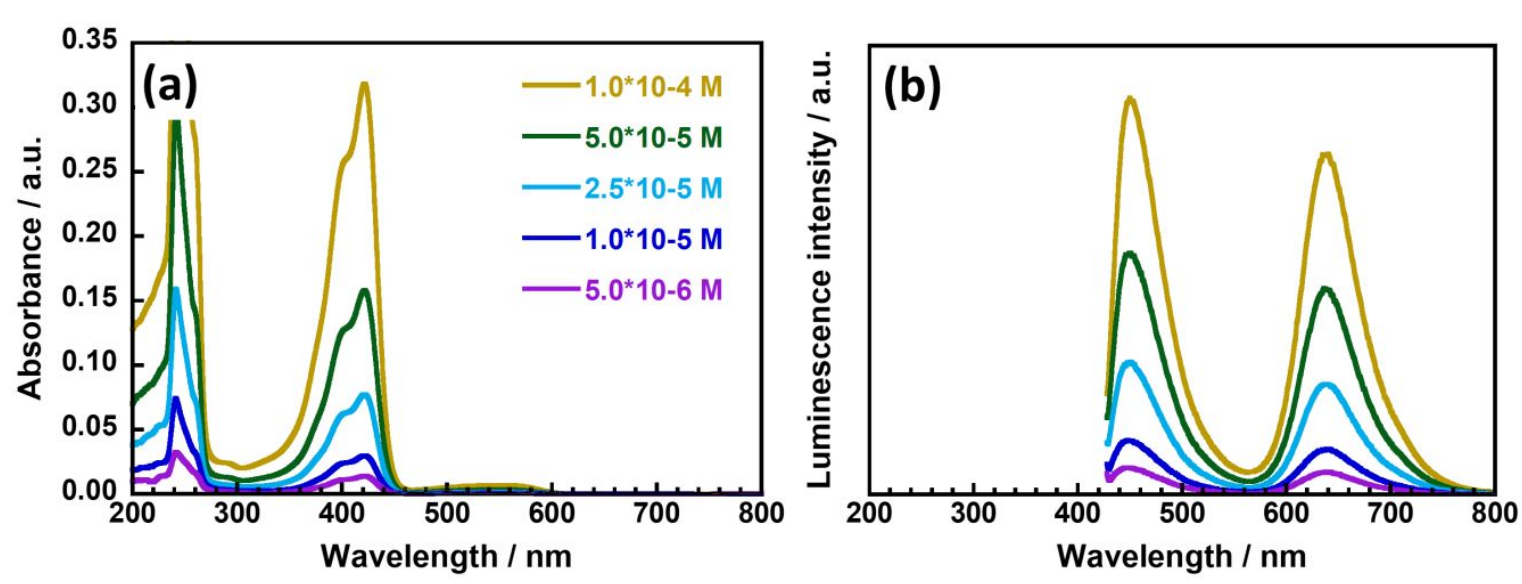

Figure S1. (a) UV-vis absorption and (b) emission spectra of DBr-MC dissolved in $\mathrm{CHCl}_{3}$. The excitation wavelength for the emission spectra was $420 \mathrm{~nm}$. 


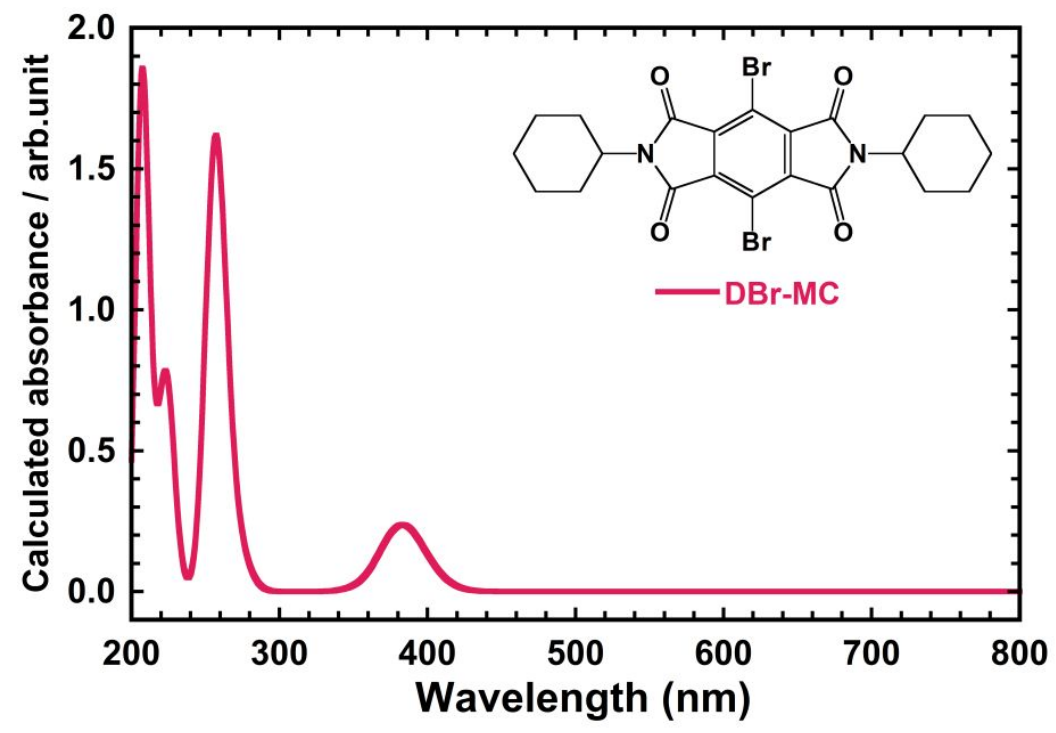

Figure S2. Calculated absorption spectrum for DBr-MC, based on TD-DFT. The peak appearing at $374 \mathrm{~nm}$ was assignable to the $\pi \rightarrow \pi^{*}$ transition of $(\mathrm{HOMO}-1) \rightarrow \operatorname{LUMO}(\lambda=$ $373.5 \mathrm{~nm}, f=0.0872$ ), and that at $260 \mathrm{~nm}$ was mainly assignable to the $\pi \rightarrow \pi^{*}$ transition of $(\mathrm{HOMO}-2) \rightarrow(\mathrm{LUMO}+1)(\lambda=253.1 \mathrm{~nm}, f=0.3960)$, where $f$ denotes the oscillator strength.

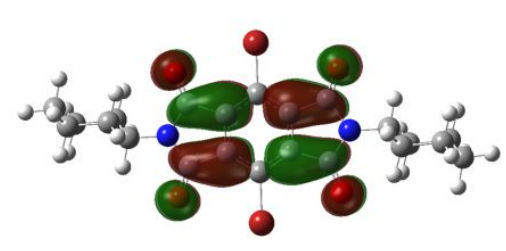

LUMO (-3.49 eV)

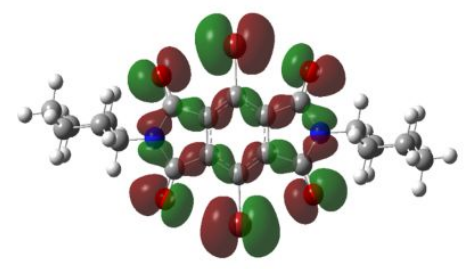

HOMO $(-7.36 \mathrm{eV})$

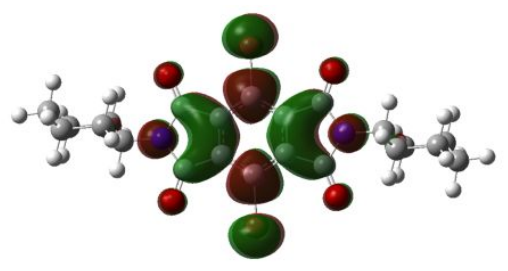

LUMO+1 (-2.36 eV)

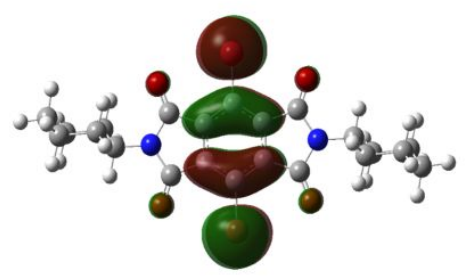

HOMO-1 (-7.41 eV)

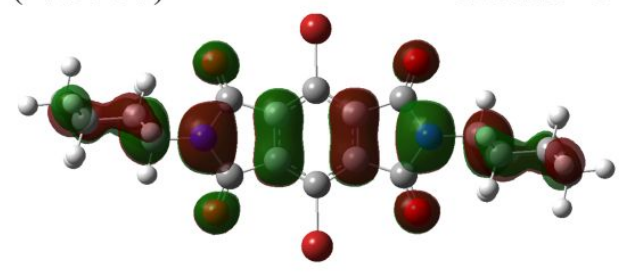

HOMO-2 (-7.78 eV)

Figure S3. Spatial distributions of DBr-MC molecular orbitals, calculated using the DFT theory $(B 3 L Y P / 6-311++G(d, p))$ 

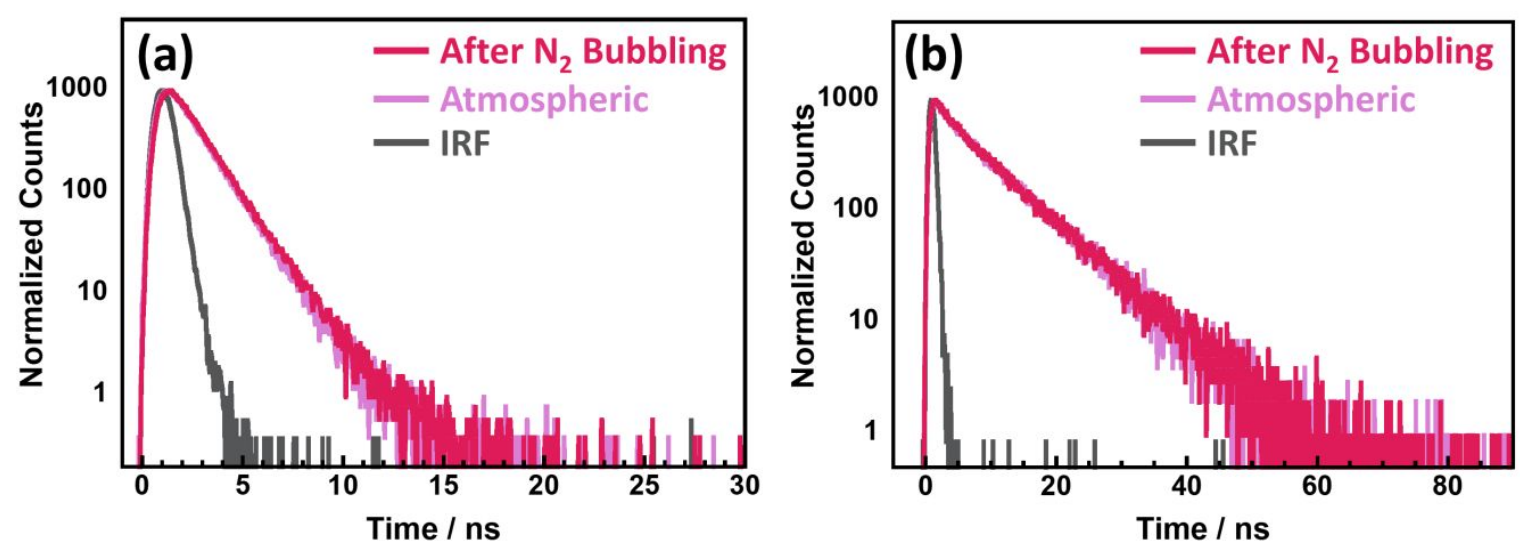

Figure S4. Luminescence decay curves for $\mathrm{DBr}-\mathrm{MC}$ dissolved in $\mathrm{CHCl}_{3}$ under atmospheric and nitrogen conditions (a) $\lambda_{\mathrm{ex}}=365 \mathrm{~nm} / \lambda_{\mathrm{em}}=440 \mathrm{~nm}$, (b) $\lambda_{\mathrm{ex}}=365 \mathrm{~nm} / \lambda_{\mathrm{em}}=640 \mathrm{~nm}$.

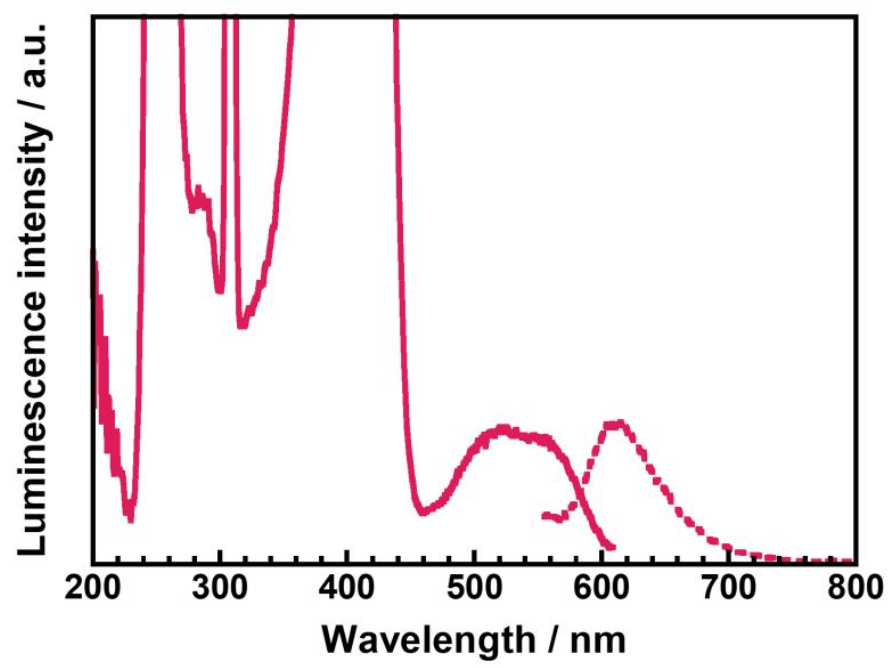

Figure S5. Excitation / emission spectra for $\mathrm{DBr}-\mathrm{MC}$ dissolved in $\mathrm{CHCl}_{3}$. The excitation wavelength for the emission spectrum was $521 \mathrm{~nm}$, and the emission wavelength for the excitation spectrum was $618 \mathrm{~nm}$. 

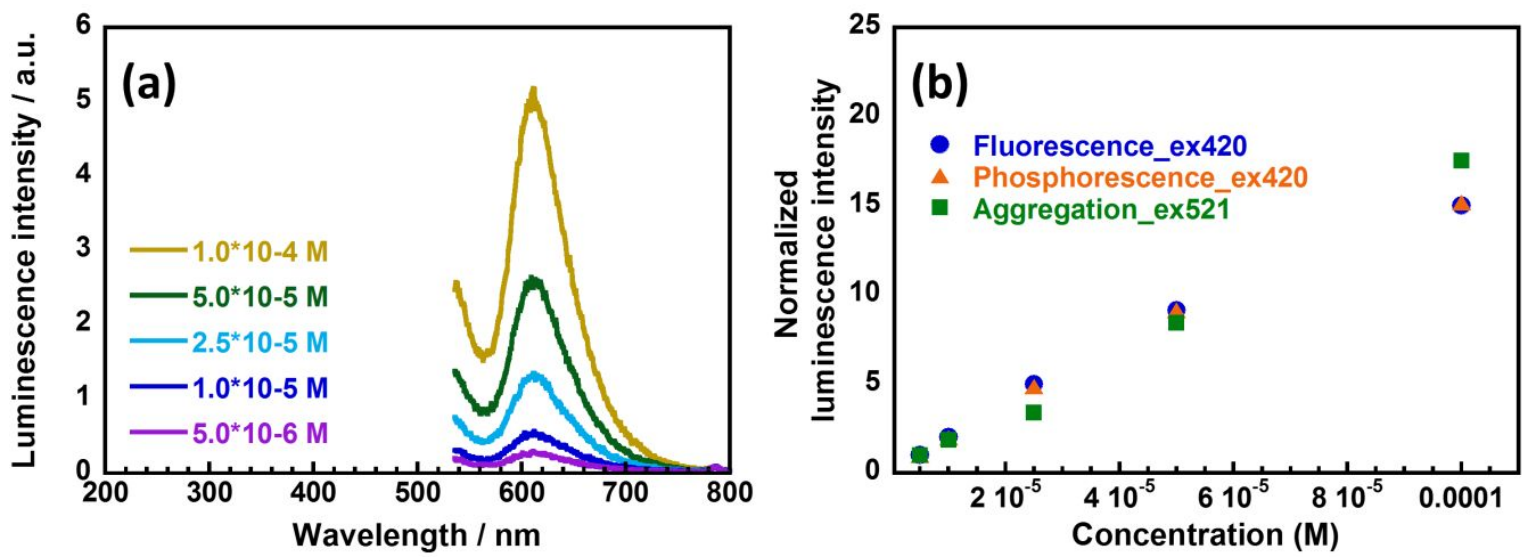

Figure S6. (a) Emission spectra for $\mathrm{DBr}-\mathrm{MC}$ dissolved in $\mathrm{CHCl}_{3}$. The excitation wavelength was $521 \mathrm{~nm}$. (b) Normalized luminescence intensities of $\mathrm{DBr}-\mathrm{MC}$ in $\mathrm{CHCl}_{3}$ at variable concentrations.

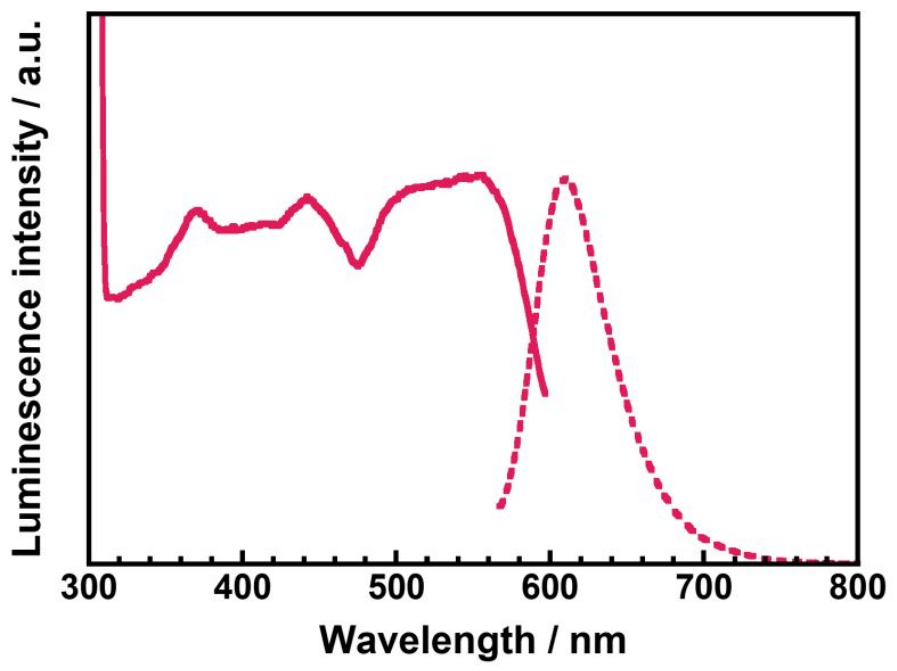

Figure S7. Excitation / emission spectra for $\mathrm{DBr}-\mathrm{MC}$ in a solid form. The excitation wavelength for the emission spectrum was $555 \mathrm{~nm}$, and the emission wavelength for the excitation spectrum was $609 \mathrm{~nm}$. 

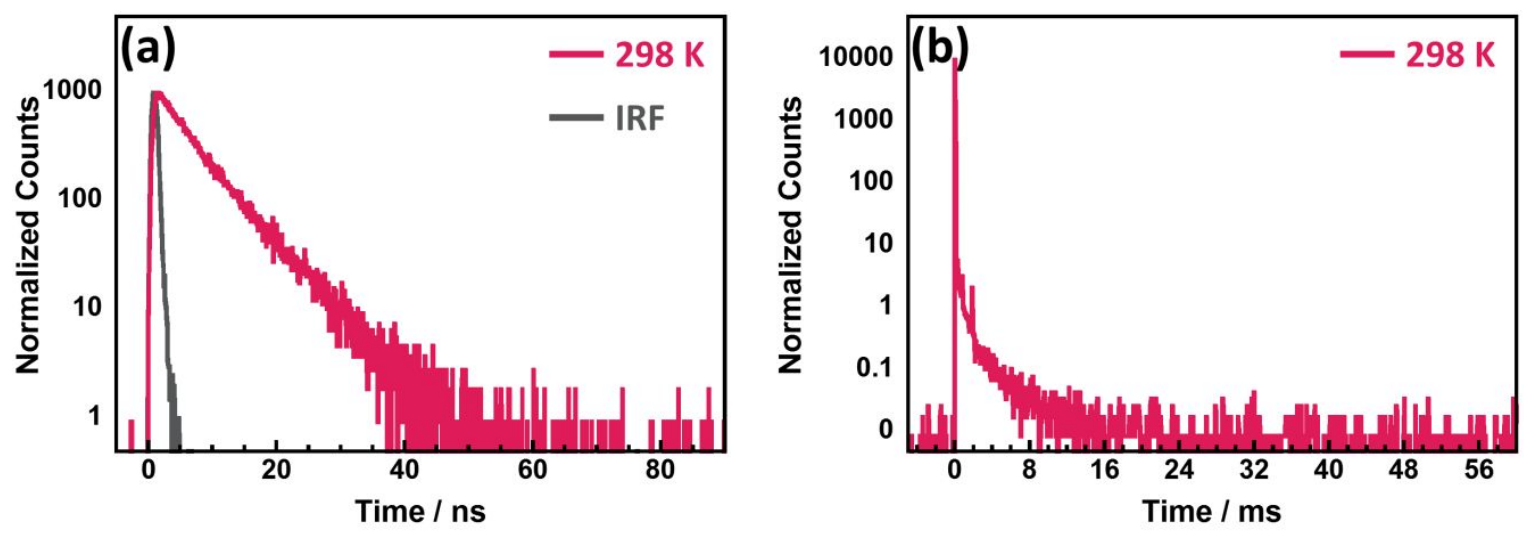

Figure S8. (a) Fluorescence decay curve $\left(\lambda_{\mathrm{ex}}=365 \mathrm{~nm} / \lambda_{\mathrm{em}}=610 \mathrm{~nm}\right)$ and (b) phosphorescence decay curve $\left(\lambda_{\mathrm{ex}}=360 \mathrm{~nm} / \lambda_{\mathrm{em}}=610 \mathrm{~nm}\right)$ for $\mathrm{DBr}-\mathrm{MC}$ in a solid form.

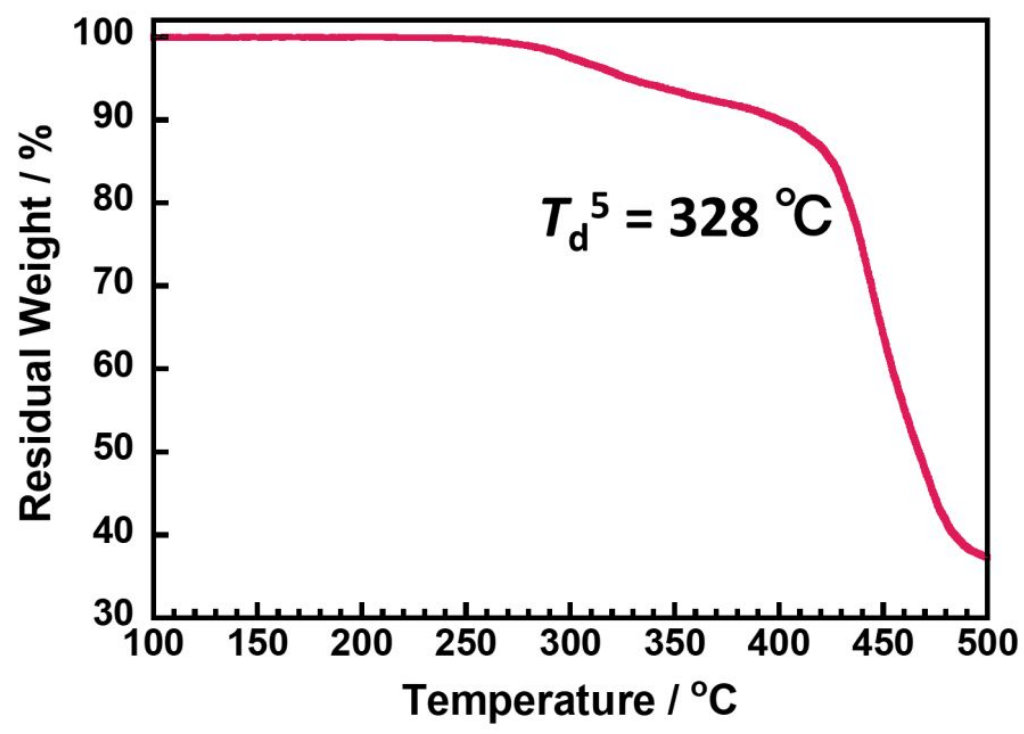

Figure S9. TGA curve of a DBr-PI thin film 


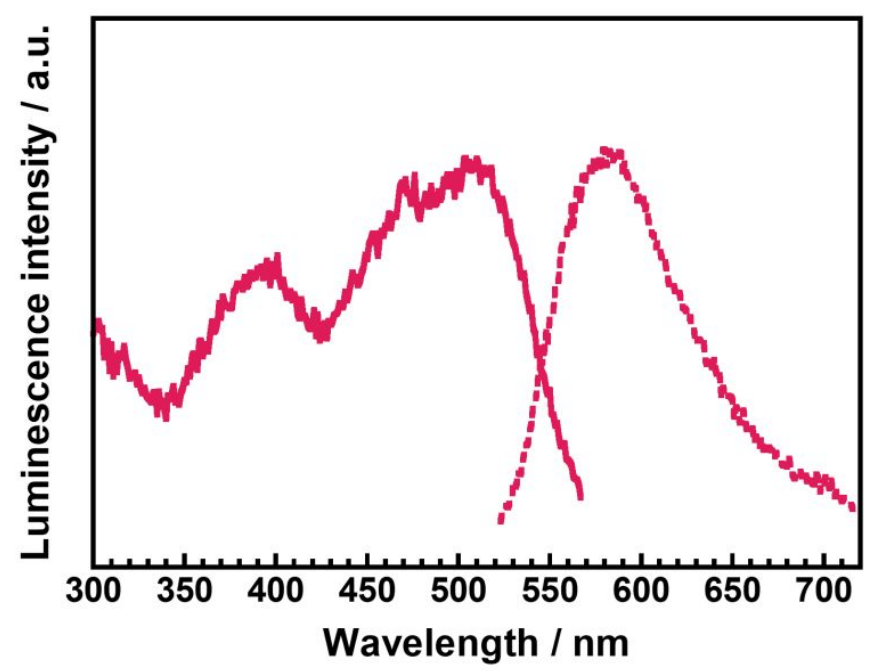

Figure S10. Excitation / emission spectra of a DBr-PI thin film. The excitation wavelength for the emission spectrum was $510 \mathrm{~nm}$, and the emission wavelength for the excitation spectrum was $580 \mathrm{~nm}$
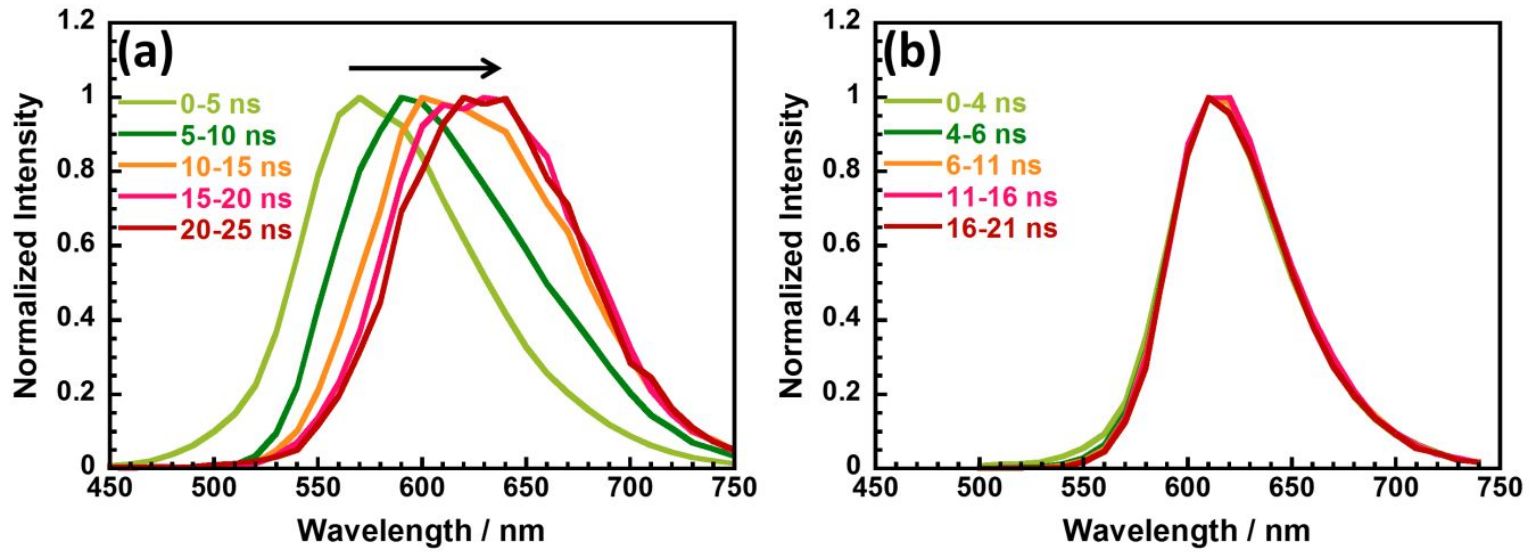

Figure S11. Time-resolved spectra for (a) DBr-PI thin film and (b) DBr-MC in a solid form at $298 \mathrm{~K}\left(\lambda_{\mathrm{ex}}=365 \mathrm{~nm}\right)$. 

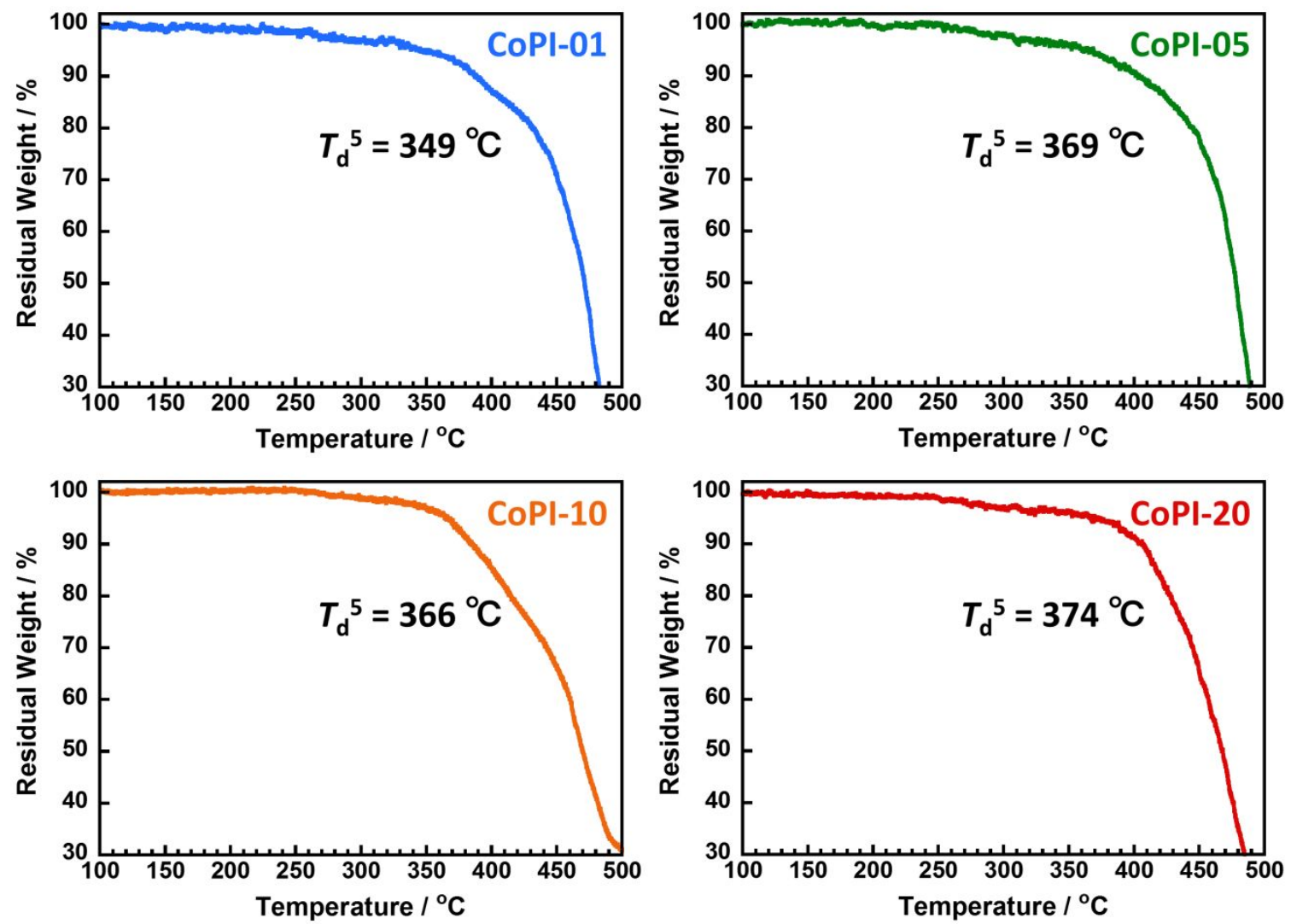

Figure S12. Thermal gravimetric analysis (TGA) curves for a series of CoPI films.

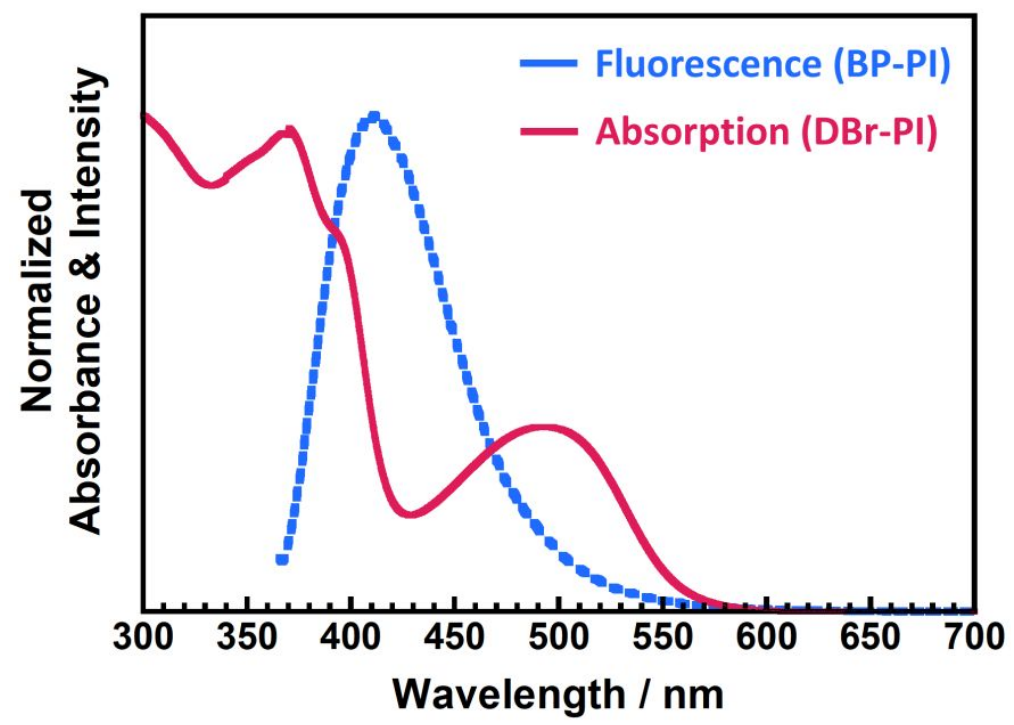

Figure S13. Spectral overlap between the absorption spectrum of DBr-PI and the fluorescence spectrum of BP-PI. 


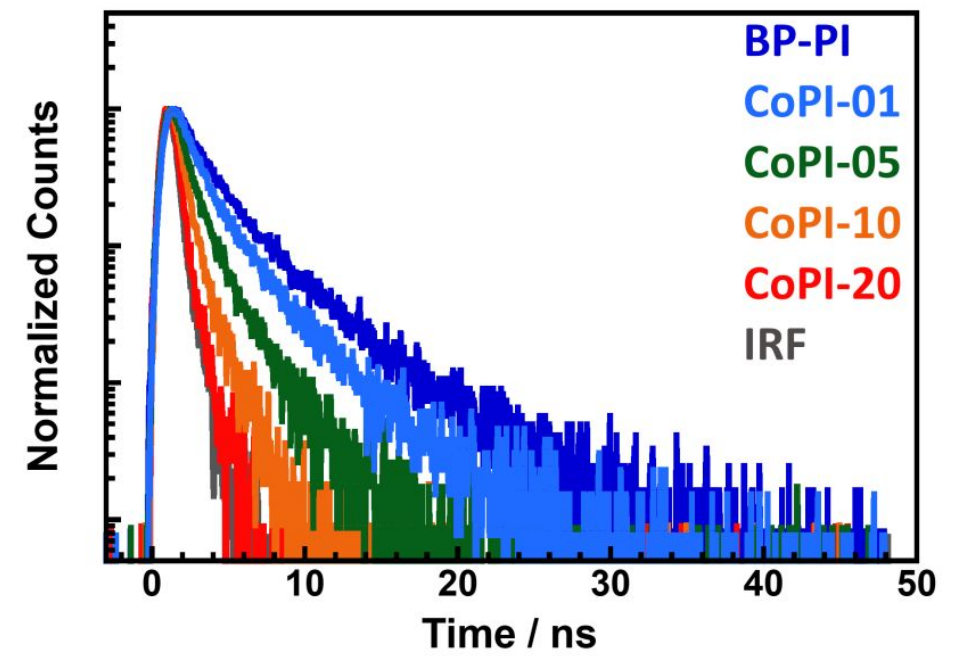

Figure S14. Fluorescence decay curves for BP-PI and CoPI films $\left(\lambda_{\mathrm{ex}}=340 \mathrm{~nm} / \lambda_{\mathrm{em}}=\right.$ $415 \mathrm{~nm})$.
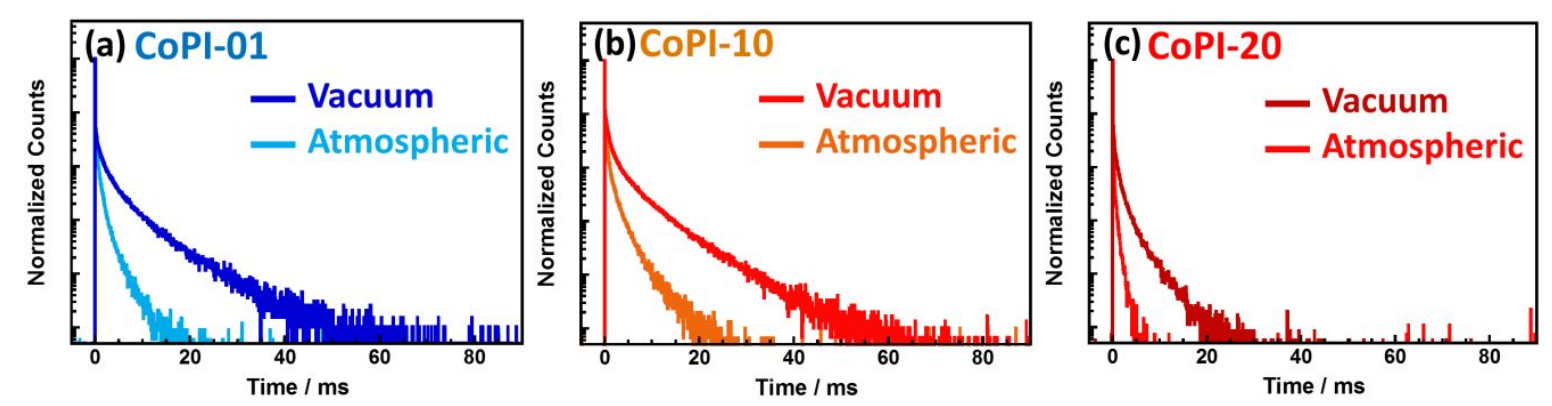

Figure S15. Phosphorescence decay curves for CoPI-01, CoPI-10, and CoPI-20 films, under atmospheric and vacuum conditions $\left(\lambda_{\mathrm{ex}}=340 \mathrm{~nm} / \lambda_{\mathrm{em}}=630 \mathrm{~nm}\right)$.
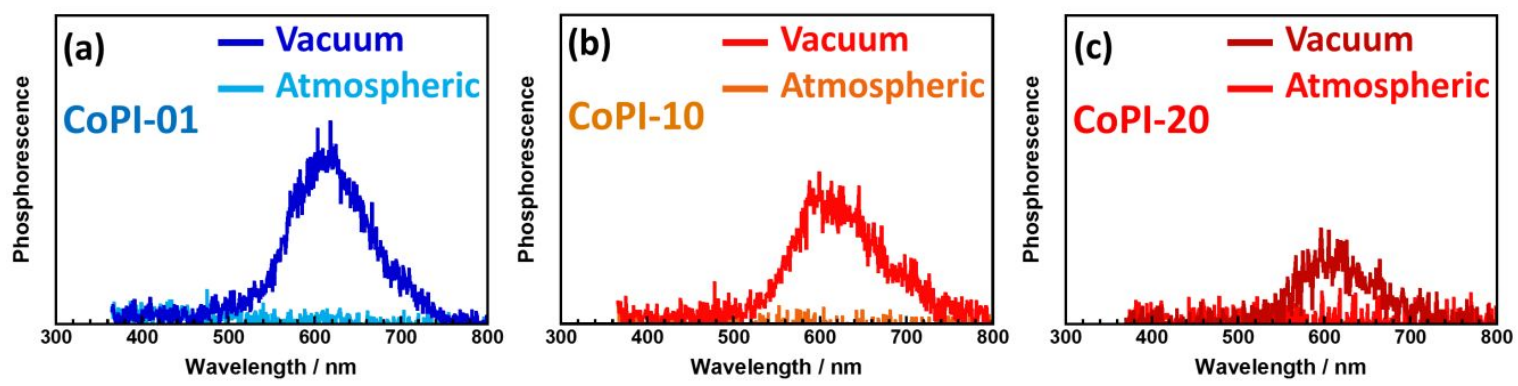
Figure S16. Phosphorescence spectra for CoPI-01, CoPI-10, and CoPI-20 films, under atmospheric and vacuum conditions $\left(\lambda_{\mathrm{ex}}=360 \mathrm{~nm}\right)$. 